\title{
Cellular Response to Surface Morphology: Electrospinning and Computational Modeling
}

\author{
Anna Denchai ${ }^{1}$, Daniele Tartarini ${ }^{2}$ and Elisa Mele ${ }^{1 *}$ \\ ${ }^{1}$ Department of Materials, Loughborough University, Loughborough, United Kingdom, ${ }^{2}$ Department of Civil Engineering, \\ University of Sheffield, Sheffield, United Kingdom
}

Surface properties of biomaterials, such as chemistry and morphology, have a major role in modulating cellular behavior and therefore impact on the development of high-performance devices for biomedical applications, such as scaffolds for tissue engineering and systems for drug delivery. Opportunely-designed micro- and nanostructures provides a unique way of controlling cell-biomaterial interaction. This minireview discusses the current research on the use of electrospinning (extrusion of polymer nanofibers upon the application of an electric field) as effective technique to fabricate

OPEN ACCESS

Edited by: Gianni Ciofani,

Politecnico di Torino, Italy

Reviewed by:

Elia Ranzato,

Università degli Studi del Piemonte

Orientale, Italy

Simona Martinotti,

Università degli Studi del Piemonte

Orientale, Italy

*Correspondence:

Elisa Mele

e.mele2@/boro.ac.uk

Specialty section:

This article was submitted to

Nanobiotechnology,

a section of the journal

Frontiers in Bioengineering and

Biotechnology

Received: 29 August 2018 Accepted: 08 October 2018

Published: 24 October 2018

Citation:

Denchai A, Tartarini D and Mele E (2018) Cellular Response to Surface Morphology: Electrospinning and Computational Modeling. Front. Bioeng. Biotechnol. 6:155. doi: 10.3389/fbioe.2018.00155 patterns of micro- and nano-scale resolution, and the corresponding biological studies. The focus is on the effect of morphological cues, including fiber alignment, porosity and surface roughness of electrospun mats, to direct cell migration and to influence cell adhesion, differentiation and proliferation. Experimental studies are combined with computational models that predict and correlate the surface composition of a biomaterial with the response of cells in contact with it. The use of predictive models can facilitate the rational design of new bio-interfaces.

Keywords: bio-interfaces, surface topography, electrospinning, micro-patterning, mathematical modeling

\section{INTRODUCTION}

The natural regeneration process of human tissues is strongly regulated by the interaction of cells with the extracellular matrix (ECM) (Lutolf and Hubbell, 2005; Liu and Wang, 2014). ECM is a dynamic and complex fibrous network of proteins and polysaccharides, such as collagen, elastin, fibronectin, laminin, proteoglycans and glycosaminoglycans. Cells interact with ECM by transmembrane receptors, known as integrins, that ligate with specific motifs of ECM proteins, for example arginine, glycine and arginylglycylaspartic acid (RGD) peptides (Anderson et al., 2016; Dalby et al., 2018). Cells continuously remodel the ECM environment, which, in turn, influences cell behavior and fate (differentiation, proliferation and migration) by biochemical, physical and mechanical signals (Geiger et al., 2001), and provides structural support to cells. Recent studies have investigated the effects of ECM physical properties, particularly porosity, topography and hierarchical 3D architecture, on cellular functions, and extrapolated rules to design structures for effective tissue regeneration (Li et al., 2017; Marino et al., 2017; Lin et al., 2018).

One of the technologies that is widely used to produce ECM-mimicking structures and particularly to replicate the fibrillar architecture of ECM is electrospinning (Khorshidi et al., 2016). The electrospinning technique allows the production of networks of fibers with a diameter in the range of few $\mathrm{nm}$ to few $\mu \mathrm{m}$ via the application of electrical forces to polymer solutions or 
melts (Bhardwaj and Kundu, 2010; Mele, 2016; Zhang et al., 2016). Structural modifications of electrospun nanofibres, such as altering topographical characteristics and inducing porosity, can be achieved by controlling and varying the process parameters (polymer concentration, applied voltage, evaporation rate of the solvent used). Similarly, changes to the final makeup of the fibrous network, such as alignment and patterning of fibers, can be obtained by modifications of the electrospinning apparatus or post-processing.

This mini review analyses a selection of recent works on the use of solution electrospinning to create nanofibres with engineered surface topography (random, aligned and patterned fibers) for controlling adhesion, differentiation, and migration of different cells lines. The mini review is divided in two main sections: the first one will focus on experimental studies on electrospun fibers that provide physical cues for cell growth and differentiation; the second section will discuss computational models to predict cell behavior on micropatterns. Although mathematical models that simulate cell behavior on electrospun fibers are not currently available, the computational approaches here discussed can be adapted, in the future, to electrospun scaffolds and used to elucidate the underlying mechanisms responsible for cell-fiber interaction.

\section{EFFECTS OF FIBER TOPOGRAPHY AND MICRO-PATTERNING ON CELLULAR RESPONSE}

Multiple studies have demonstrated that the morphology and roughness of fibers produced by electrospinning influence cell adhesion, proliferation, and orientation (Sill and von Recum, 2008; Xie et al., 2008; Bergmeister et al., 2013; Cirillo et al., 2014; Zhu et al., 2015; Sun et al., 2018). All factors that are imperative for successful tissue regeneration (Agarwal et al., 2008). Cells can sense topographical structures on a surface by filipodia that are actin-rich protrusions $(0.1-0.3 \mu \mathrm{m}$ in diameter) of the cell membrane and are involved in cell contact guidance (Mattila and Lappalainen, 2008; Dalby et al., 2014). If nanoscale aligned features are present onto a surface, filopodia tend to orient along the direction of the features and determine cytoskeleton orientation. Focal adhesions at the cell membrane mediate the initial cell-biomaterial interaction, with integrin ligands in direct contact with the substrate and connected to the actin microfilaments of the cell cytoskeleton by a 40-nm stratum, which includes focal adhesion kinase (FAK), paxillin, talin, and vinculin (Kanchanawong et al., 2010).

This section of the review will discuss how electrospun mats with controlled porosity and surface morphology have been used to influence the behavior of mesenchymal stem cells (MSCs) (Jiang et al., 2015; Yin et al., 2015; Baudequin et al., 2017; Lin et al., 2017; Liu et al., 2017; Nedjari et al., 2017; Su et al., 2017; Zhang et al., 2017; Ghosh et al., 2018; Jin et al., 2018; Rahman et al., 2018; Sankar et al., 2018) and human umbilical vein endothelial cells (HUVECs) (Fioretta et al., 2014; Xu et al., 2015; Shin et al., 2017; Taskin et al., 2017; Yan et al., 2017; Ahmed et al., 2018). The literature on other cell lines, such as on myoblasts (Mele et al., 2015; Jun et al., 2016; Park et al., 2016; Tallawi et al., 2016; Abarzúa-Illanes et al., 2017; Yang et al., 2017) and neuron-like cells (Binan et al., 2014; Xie et al., 2014; Malkoc et al., 2015; Xue et al., 2017; Hajiali et al., 2018; Xia and Xia, 2018), will not be analyzed in detail here but a summary of it is reported in Table $\mathbf{1}$.

\section{Mesenchymal Stem Cells}

MSCs are multipotent stem cells that are primarily isolated from bone marrow, but they can also be found in adipose tissue, dental pulp, placenta, umbilical cord and other vascularized tissues throughout the body (Lv et al., 2014; Tartarini and Mele, 2015). MSCs are of great interest in regenerative medicine, because of their therapeutic effects, such as: ability to differentiate into various cell types and therefore promote regeneration of a wide range of tissues (bone, cartilage, muscle, marrow, tendon, ligament, nervous tissue, and skin); secretion of bioactive molecules for tissue repair; migration to inflamed tissues and modulation of local inflammation; immunomodulatory functions (Sharma et al., 2014).

In a recent research, Zhang et al. have studied how the topography and fibrillar organization of electrospun poly ( $\varepsilon$ caprolactone) (PCL) fibers influences the recruitment of MSCs in vivo and ex vivo (Zhang et al., 2017). PCL mats (randomly distributed fibers) were implanted into the subcutaneous tissue of rats and the results were compared with solid PCL films (not electrospun). It was observed that, during the initial postimplantation period (1 day), a great number of macrophages with M1 phenotype (pro-inflammatory) were recruited to the PCL fibers, differently from solid PCL. This was attributed to the high surface area of the fibers and the porosity of the electrospun mats that promoted protein adsorption from the surrounding tissue, such as complement C3a (a chemo-attractant responsible to activate and recruit immune cells), fibronectin and vitronectin. After 4 and 7 days of implantation, the PCL fibers attracted host MSCs and modulated macrophages polarization with an increased number of cells exhibiting M2 (pro-healing) phenotype. While the number of M2 cells continuously increased over the entire period of implantation for PCL fibers, this was not the case for solid PCL where a large population of M1 cells was retained. Migration of MSCs was also observed in ex vivo experiments conducted with the implanted PCL samples. It was found that the macrophages at the implanted PCL mats secreted high levels of SDF-1, a chemokine that mediates MSCs recruitment by interacting with CXC chemokine receptors on the MSCs membrane. The study concluded that the physical organization of the PCL electrospun network induced the phenotype M1-to-M2 transition of macrophages that attracted MSCs at the implantation site by releasing SDF-1. This cascade of events was beneficial to stimulate tissue repair. PCL electrospun fibers have been used also to stimulate the production of pro-angiogenic and anti-inflammatory paracrine factors in rat adipose-derived MSCs (Ad-MSCs) (Su et al., 2017) and in skin excisional wound-healing model in rats (Table 2). Ad-MSCs were seeded on three types of electrospun PCL fibers, random (REF), aligned (AEF) and with a mesh pattern (MEF). It was observed that scaffolds with oriented fibers (AEF and MEF) promoted the expression of PGE2 
TABLE 1 | Summary of the recent literature on the use of electrospun fibers to control morphology, alignment and differentiation of diverse cell lines.

\begin{tabular}{|c|c|c|c|c|}
\hline Cells & Material & Fiber characteristics & Main outcomes & References \\
\hline Human MSCs & Poly ( $\varepsilon$-caprolactone) & $\begin{array}{l}\text { Randomly distributed fibers; Diameter: } \sim \\
630 \mathrm{~nm} \text {; Surface roughness: } \sim 2 \mu \mathrm{m} .\end{array}$ & $\begin{array}{l}\text { Recruitment of MSCs in vivo and ex vivo; } \\
\text { Recruitment of macrophages in vivo; } \\
\text { Phenotype transition of adhered }\end{array}$ & $\begin{array}{l}\text { Zhang et al., } \\
2017\end{array}$ \\
\hline
\end{tabular}

Human MSCs

Human MSCs

Human

adipose-derived MSCs

Human

adipose-derived MSCs

Human bone marrow

MSCs

Human dental pulp Polystyrene

MSCs

Mouse MSCs

(C3H10T1/2)

Mouse MSCs

(C3H10T1/2)

Rat bone marrow MSCs

Rat bone marrow MSCs

Rat adipose-derived MSCs

HUVECS gelatine fibrinogen
Poly ( $\varepsilon$-caprolactone); Poly ( $\varepsilon$-caprolactone)-

Poly (L-lactic acid)

Poly (L-lactide $\varepsilon$-caprolactone) and

SU-8 photoresist

Poly ( $\varepsilon$-caprolactone)

Poly (L-lactic acid)

Random and aligned fibers; Diameter: 740-1070 nm. polycaprolactone

Poly ( $\varepsilon$-caprolactone) and poly (ethylene glycol); Chitosan coated with poly $950 \mathrm{~nm}$.

Random and aligned fibers; Diameter: using honeycomb shaped collector width and $60 \mu \mathrm{m}$ height.

Randomly oriented fibers; Diameter: photolithography; Pattern dimensions: height.

Random-aligned-random structure; Diameter: 240-450 nm.

Random and aligned coaxial fibers; Diameter: $\sim 2 \mu \mathrm{m}$; Porosity: 82-84\%.

Random and aligned fibers; Diameter:
Polylactic acid and

Randomly distributed and aligned fibers; Diameter: 600-780 nm; Porosity: 78-86\%.

Randomly distributed and aligned fibers

(3,4-ethylenedioxythiophene; Diameter: 200-500 nm; Patterning of electrospun mats produced by photolithography; Honeycomb: $160 \mu \mathrm{m}$ internal diameter, walls of $20 \mu \mathrm{m}$ $550 \mathrm{~nm}$; Patterning of electrospun mats by $20 \mu \mathrm{m}$ ridges, $20 \mu \mathrm{m}$ grooves, $5 \mu \mathrm{m}$ pattern

Randomly distributed fibers; Diameter: 300-500 nm; Surface roughness: $0.8 \mu \mathrm{m}$. 200-600 nm; 3D multi-layered scaffolds: layers of fibers within a porous chitosan matrix.

Poly ( $\varepsilon$-caprolactone)

Random and aligned fibers; Diameter: 820-1000 nm; Application of mechanical tension-stress after cell seeding.

Poly ( $\varepsilon$-caprolactone)

Random and aligned fibers; Diameter: $1 \mu \mathrm{m}$; Patterning of electrospun mats using copper mesh with grid length of $830 \mu \mathrm{m}$ as collector.

Poly (D,L-lactide) and polycaprolactone
Random and aligned fibers; Diameter: 500-700 nm; Patterning of electrospun mats using a wire spring with interval distances of 300,800 , and $1500 \mu \mathrm{m}$ as collector.

macrophages from pro-inflammatory (M1) to pro-healing (M2).

\section{Cardiomyogenesis; Cytoskeletal} arrangement; Changes in the cellular and nuclear morphology.

Synergic effect of fiber alignment and electrical stimulation; Promotion of cellular activity and proliferation.

Homotypic interaction of MSCs on honeycomb scaffolds; Osteogenic differentiation of MSCs on honeycomb scaffolds.

Orientation and alignment of cells resembling the in vivo anisotropic multilamellar architecture of bone; Osteodifferentiation of MSCs.

Regional induction of MSCs toward tenogenesis and osteogenesis; Collagen deposition.

Increased the expression of bone morphogenetic proteins and Wnt ligands; Odontoblast differentiation of MSCs; Dentin regeneration.

Up-regulation of tendon-specific markers for MSCs on aligned fibers; Tendon-like tissue regeneration in vivo for aligned fibers; Bone formation in vivo for random fibers.

Expression of tendon-related markers; Tenogenic differentiation of mouse MSCs.

Ligamentogenesis and partially decreased osteogenesis for MSCs for aligned nanofibers embedded scaffolds in vitro; Regeneration of periodontal ligament in vivo for aligned nanofibers embedded scaffolds; High expression levels of periostin and formation of tooth-supporting mineralised tissue in the regenerated periodontium for aligned scaffolds.

Osteogenic differentiation of MSCs onto aligned fibers; Expression of osteogenic genes on aligned fibers; enhanced expression of osteogenic genes after mechanical stimulation.

Upregulated levels of anti-inflammatory and pro-angiogenic cytokines in vitro for MSCs on patterned mats; Therapeutic effects of the fibers in a skin excisional healing model in vivo.

Modification of cytoskeleton morphology; Cell alignment and polarization on aligned fibers; Expression of angiogenesis-related genes.
Ghosh et al., 2018

Jin et al., 2018

Nedjari et al., 2017

Sankar et al., 2018

Lin et al., 2017

Rahman et al., 2018

Yin et al., 2015

Baudequin et al., 2017

Jiang et al., 2015

Liu et al., 2017

Su et al., 2017

Xu et al., 2015

(Continued) 
TABLE 1 | Continued

\begin{tabular}{|c|c|c|c|c|}
\hline Cells & Material & Fiber characteristics & Main outcomes & References. \\
\hline HUVECS & $\begin{array}{l}\text { Polycaprolactone and } \\
\text { polyethyleneoxide }\end{array}$ & $\begin{array}{l}\text { Nanostructured, random fibers. Diameter: } \\
\text { 4-20 } \mu \mathrm{m} \text {. }\end{array}$ & $\begin{array}{l}\text { Enhanced cells' proliferation; Stimulation of } \\
\text { adhesion complex formation on } \\
\text { nanotextured fibers. }\end{array}$ & $\begin{array}{l}\text { Taskin et al., } \\
2017\end{array}$ \\
\hline HUVECS & Poly (L-lactide) & $\begin{array}{l}\text { Random and aligned fibers; Patterning of } \\
\text { electrospun mats by femtosecond laser } \\
\text { ablation; Pattern dimensions: grooves } \\
\text { distance of } 20.9 \text { and } 81.3 \mu \mathrm{m} \text {; grooves } \\
\text { width of } 9.4 \text { and } 7.6 \mu \mathrm{m} \text {; grooves depth of } \\
12.5 \text { and } 13.9 \mu \mathrm{m} \text {. }\end{array}$ & $\begin{array}{l}\text { Changes in morphology and orientation of } \\
\text { cells on micropatterned scaffolds; Reduction } \\
\text { of monocytes adhesion on the } \\
\text { micropatterned mats; Anti-inflammatory } \\
\text { response. }\end{array}$ & Shin et al., 2017 \\
\hline HUVECS & Poly (L-lactic acid) & $\begin{array}{l}\text { Random fibers; Diameter: } 540 \mathrm{~nm} \text {; } \\
\text { Patterning of electrospun mats by hot } \\
\text { embossing; Pattern dimensions: } 50,100 \text {, } \\
\text { and } 200 \mu \mathrm{m} \text { wide grooves. }\end{array}$ & $\begin{array}{l}\text { Cells alignment along the direction of the } \\
\text { grooves; Expression of endothelial } \\
\text { biomarkers by cells cultured on } \\
\text { micropatterned scaffolds. }\end{array}$ & Yan et al., 2017 \\
\hline HUVECS & $\begin{array}{l}\text { Poly (lactic-co-glycolic } \\
\text { acid) }\end{array}$ & Aligned fibers; Diameter: 0.5-10 $\mu \mathrm{m}$. & $\begin{array}{l}\text { Cell alignment and polarization on fibers with } \\
\text { intermediate diameter; Stimulation of a } \\
\text { migratory phenotype. }\end{array}$ & $\begin{array}{l}\text { Ahmed et al., } \\
2018\end{array}$ \\
\hline $\begin{array}{l}\text { C2C12 myoblasts and } \\
\text { neonatal rat } \\
\text { cardiomyocytes }\end{array}$ & $\begin{array}{l}\text { Poly (glycerol sebacate) } \\
\text { and poly (caprolactone) }\end{array}$ & $\begin{array}{l}\text { Random fibers; Diameter: } 1.2 \mu \mathrm{m} \text {; } \\
\text { Patterning of electrospun mats using a } \\
\text { microstructured collector; Parallel grooves of } \\
10 \mu \mathrm{m} \text { diameter and interspatial distances of } \\
200 \text { and } 7 \mu \mathrm{m} \text {; Square-shaped structures of } \\
100 \mu \mathrm{m} \text { size and } 50 \mu \mathrm{m} \text { distance. Surface } \\
\text { roughness: } 0.4-1.3 \mu \mathrm{m} \text {. }\end{array}$ & $\begin{array}{l}\text { Cells alignment along parallel grooves } \\
\text { topography. }\end{array}$ & $\begin{array}{l}\text { Tallawi et al., } \\
2016\end{array}$ \\
\hline C2C12 myoblasts & Poly (caprolactone) & $\begin{array}{l}\text { Random and aligned fibers; Diameter: } \\
0.8-2.5 \mu \mathrm{m} \text {. Distance between aligned } \\
\text { fibers: } 2.2 \text { and } 13.8 \mu \mathrm{m} \text {. }\end{array}$ & $\begin{array}{l}\text { Uniaxial orientation and elongation of cells } \\
\text { on aligned fibers; Myogenic differentiation } \\
\text { and elongation of myotubes along the } \\
\text { aligned fibers. }\end{array}$ & Park et al., 2016 \\
\hline C2C12 myoblasts & Poly (L-lactic acid) & $\begin{array}{l}\text { Random fibers; Diameter: } 720 \mathrm{~nm} \text {; } \\
\text { Patterning of electrospun mats using a } \\
\text { femtosecond laser ablation; Parallel grooves } \\
\text { of } 5 \mu \mathrm{m} \text { width and spacing of } 10,25 \text {, and } \\
80 \mu \mathrm{m} \text {. }\end{array}$ & $\begin{array}{l}\text { Cells alignment along the micro-grooves; } \\
\text { Regulation of cellular adhesive morphology, } \\
\text { proliferation, and distribution of focal } \\
\text { adhesion proteins. }\end{array}$ & Jun et al., 2016 \\
\hline C2C12 myoblasts & $\begin{array}{l}\text { Poly ( } \varepsilon \text {-caprolactone) } \\
\text { and poly } \\
\text { (lactic-co-glycolic acid) }\end{array}$ & $\begin{array}{l}\text { Random and aligned fibers; Diameter: } \\
0.4-3.2 \mu \mathrm{m} \text {; }\end{array}$ & $\begin{array}{l}\text { Increased alignment and aspect ratio of } \\
\text { myotubes on aligned fibers. }\end{array}$ & $\begin{array}{l}\text { Abarzúa-Illanes } \\
\text { et al., } 2017\end{array}$ \\
\hline Neuron-like PC12 cells & $\begin{array}{l}\text { Poly (caprolactone) and } \\
\text { gelatin; Collagen; } \\
\text { Polystyrene }\end{array}$ & $\begin{array}{l}\text { Random fibers; Diameter: } 440 \mathrm{~nm} \text {; } \\
\text { Patterning of electrospun mats using } \\
\text { polystyrene } 5 \mu \mathrm{m} \text { wide grooves and } 18 \mu \mathrm{m} \\
\text { diameter wells by thermal fusion. }\end{array}$ & $\begin{array}{l}\text { Increased extension of neurites within the } \\
\text { grooves; High neurite length per } \\
\text { differentiated cell for the micropatterned } \\
\text { substrates. }\end{array}$ & $\begin{array}{l}\text { Malkoc et al., } \\
2015\end{array}$ \\
\hline Neural stem cells & Polyphenylene sulfone & $\begin{array}{l}\text { Random and aligned fibers; Diameter: } \\
735 \mathrm{~nm} .\end{array}$ & $\begin{array}{l}\text { Enhanced neuronal differentiation on the } \\
\text { fibrous scaffolds; Growth and activity of } \\
\text { primary neural cells on nanofibres; Parallel } \\
\text { axon growth on aligned nanofibers. }\end{array}$ & $\begin{array}{l}\text { Hajiali et al., } \\
2018\end{array}$ \\
\hline
\end{tabular}

(Prostaglandin E2, a potent inflammatory mediator), iNOS (inducible Nitric Oxide Synthase), VEGF (vascular endothelial growth factor) and HGF (hepatocyte growth factor), compared to REF scaffolds. In order to elucidate the molecular signaling mechanism responsible for the paracrine secretion of Ad-MSCs, the cells were treated with an inhibitor of NF-kB (a transcription factor that induces the expression of pro-inflammatory genes) and this significantly reversed the paracrine response of MSCs to the electrospun scaffolds. The authors therefore speculated that, in the presence of the scaffolds, MSCs behaved as if they were exposed to an external inflammatory stimulus. Similar results have been recently reported for MSCs cultured on electrospun fibers of PCL/polytetrahydrofuran (PTHF) urethane (P fibers) and PCL-PTHF urethane/collagen I (PC fibers) (Jiang et al., 2018). In this case, down-regulation of genes that contribute to inflammation and suppression of the NF-kB pathway signaling pathway were achieved by changing the mechanical properties of the fibers. PC fibers with a Young's modulus of 4.3 MPa were able to suppress inflammation, differently from P fibers (Young's modulus of $6.8 \mathrm{MPa}$ ).

Another study has investigated how electrospun PCL scaffolds with a novel random-aligned-random structure can be used to mimic bone-ligament connections and native ligaments (Lin et al., 2017). The authors designed a fiber collecting device for the fabrication of electrospun scaffolds with a controlled spatial distribution of random and aligned fibers. 
TABLE 2 | Summary of main results reported in selected recent papers on electrospun scaffolds used in vivo experiments.

Scaffolds

Mono-component (MC) and bi-component (BC) conduits made of random PCL and PCL/gelatin fibers, respectively, implanted in rat sciatic nerve defects.

Random and aligned PCL-PEG fibers within a chitosan matrix implanted in a surgically created defect in maxillary first molar of rats.

Vascular grafts with oriented PCL microfibers coated with electrospun random PCL nanofibres and implanted in rat abdominal aorta.

Random PCL fibers implanted into the subcutaneous tissues of rats.

Conditioned-medium (CM) from Ad-MSCs cultured on oriented (AEF and MEF) PCL fibers. CM applied to a skin wound-healing model.

PCL-PTHF urethane (P fibers) and PCL-PTHF urethane/collagen I (PC fibers) implanted in defects on the surface of the patellar groove of rat femurs.

Random and aligned PCL/Collagen I fibers used to treat full-thickness wounds in diabetic rats.
In vivo outcomes

References

Formation of numerous myelinated axons and vasculature in the MC conduit group; fibrous tissue and inflammatory cells with no Cirillo et al., 2014 evidence of myelinated axons for BC conduits, due to gelatin degradation or mechanical collapse.

Superior functional recovery recorded for $\mathrm{MC}$ conduits over BC conduits after 18 weeks of implantation.

Recover of tibialis anterior and gastrocnemius muscle weights after 18 weeks for MC conduit group; muscle atrophy for BC conduit group.

Rat bone marrow mesenchymal stem cells (rBMSCs) with spindle shape and oriented actin filaments on scaffolds consisting of aligned fibers; while rBMSCs with polygonal or dentritic shape of scaffolds with random fibers.

Increased ligamentogenesis and partially decreased osteogenesis for rBMSCs for scaffolds with aligned fibers.

Increased stability and maturation of the periodontal ligament matrix, and increased regenerated bone volume and density for scaffolds with aligned fibers.

Enhanced growth of vascular smooth muscle cells (VSMCs) after 2 and 4 weeks of implantation.

Regeneration of arteries with notable VSMCSs vaso-activity after 12 weeks of implantation, and synthesis of elastin and collagen type I/II with phenotypic and structural similarities to the native arteries.

Complete endothelialisation after 4 weeks with endothelial cells (ECs) having a morphology similar to the native endothelium. Regeneration of healthy and functional neaoarteries where VSMCs and ECs response to the endothelial-specific activator acetylcholine, hence showing vasodilation.

Macrophage recruitment, elongation and increased the expression of Arginase-1 or IL-4.

Macrophage phenotype transition from M1 (pro-inflammatory) to M2 (pro-healing).

High adsorption of proteins, particularly the chemotactic factor Complement $\mathrm{C} 3 \mathrm{a}$, vitronectin and fibronectin.

Macrophages' secretion of high levels of SDF-1, a chemokine that mediates MSCs recruitment by interacting with CXC chemokine receptors on the MSCs membrane.

High wound closure rate for animals treated with the MSC-MEF CM.

Collagen deposition in a fine reticular pattern for group of MSC-MEF CM.

High density of macrophages and M2 macrophages for MSC-MEF CM.

After 4 weeks of implantation, newly formed tissues for both $\mathrm{P}$ and PC groups with minor inflammatory cells after 4 weeks. Fibrous tissue with a loose and detached for $\mathrm{P}$ group; fibrocartilage-like tissue and integration with the surrounding tissue for PC group. After 8 weeks of implantation, hyaline cartilage with round cells in the lacuna for both $\mathrm{P}$ and $\mathrm{PC}$ groups. More uniform and compact tissue for PC group.

Stronger positive immunohistochemical staining of collagen II for PC group after 4 weeks.

Remarkable increase of the expression of Arginase I and NOS2 for oriented fibers and consequent stimulation of macrophages transition from $\mathrm{M} 1$ to $\mathrm{M} 2$.

Detection of new blood vessels at the wound site for scaffolds with oriented fibers.

Infiltration of fibroblasts and macrophages and collagen deposition in the wound sites for all nanofiber groups.
Jiang et al., 2015

Zhu et al., 2015

Zhang et al. 2017

Su et al., 2017

Jiang et al., 2018

Sun et al., 2018

(Continued) 
TABLE 2 | Continued

\begin{tabular}{|c|c|c|}
\hline Scaffolds & In vivo outcomes & References \\
\hline $\begin{array}{l}\text { Random and aligned PLLA fibers implanted in rats for } \\
\text { Achilles tendon repair. }\end{array}$ & $\begin{array}{l}\text { After implantation, for scaffolds with aligned fibers, tendon-like } \\
\text { tissue formation, continuous collagen fibers, expression of } \\
\text { tendon-specific markers, such as scleraxis, tenomodulin, and } \\
\text { Msx-2 (role in preventing tendons from mineralizing). } \\
\text { After implantation, for scaffolds with random fibers, substantial } \\
\text { chondrogenesis and tissue ossification, high levels of } \\
\text { chondro-lineage specific genes, such as collagen type II, Sox9, } \\
\text { and aggrecan. }\end{array}$ & Yin et al., 2015 \\
\hline $\begin{array}{l}\text { Polyurethane (PU) grafts with low (void fraction of } 53 \% \text { ) } \\
\text { and high (void fraction of } 80 \% \text { ) porosity, implanted into } \\
\text { the infrarenal aorta of rats. }\end{array}$ & $\begin{array}{l}\text { Growth of vimentin-positive fibroblasts, actin-positive } \\
\text { myofibroblasts and desmin-positive myocytes at the adventitial } \\
\text { interface of the grafts in the early phase after implantation. } \\
\text { Growth of myofibroblasts and myocytes within the whole graft wall } \\
\text { of the coarse-mesh grafts, } 6 \text { months after implantation; while } \\
\text { limited cell growth for fine-mesh grafts. } \\
\text { Superior cell migration and long-term survival of cells for grafts } \\
\text { with high porosity than for grafts with low porosity. }\end{array}$ & $\begin{array}{l}\text { Bergmeister } \\
\text { et al., } 2013\end{array}$ \\
\hline
\end{tabular}

The regions of the scaffold with random fibers were then mineralized with Ca-P. In vitro tests on human bone marrow MSCs (hBMSCs) revealed that fiber anisotropy modified cells' morphology: polygonal, round-shaped cells without alignment were detected in the random, mineralized regions of the scaffold; while elongated spindle-shaped cells aligned along the fiber direction were visible in the aligned region. Moreover, the aligned fibers significantly up-regulated tendon-specific and tendon-related markers (Tnmd, $\mathrm{Mkx}$ ) and therefore guided tenogenic phenotypes of hBMSCs; while, the regions with random, mineralized fibers determined the expression of bone-specific markers (Runx-2, Ocn, Opn) and consequently hBMSCs osteogenic phenotypes. Although the authors have not elucidated the underlying cell signaling mechanisms, this work demonstrates that electrospun scaffolds with engineered fiber anisotropy are advantageous to achieve region-specific distribution of tendon- and bone-related genes and find potential application in ligament repair and regeneration of bone-ligament connections.

The possibility to mediate the expression of signaling biomolecules by electrospun fibers and hence guide MSCs differentiation has been demonstrated also by Rahman and co-workers (Rahman et al., 2018). They investigated the odontoblastic differentiation of human dental pulp MSCs (DP-MSCs) on polystyrene (PS) random fibers. The cells cultured on PS mats strongly increased the expression of bone morphogenetic proteins (BMPs) and Wnt ligands that are essential in tooth development: Wnt3a transcript expression was more than 50 folds higher after 4 days of culturing on PS fibers than on standard petri dishes. The levels of odontoblast/osteoblast markers, such as dentin sialophosphoprotein (DSPP), osteocalcin, and bone sialoprotein, were also higher for DP-MSCs cultured on electrospun fibers. The results of this study indicate that nanofibres mimicking the in vivo microenvironment are crucial to stimulate the differentiation of DP-MSCs into odontoblasts (specialized cells responsible for dentin formation) by mediating the production of signaling molecules including $\mathrm{Wnt} 3 \mathrm{a}$, and to promote dentinogenesis. Osteogenesis of MSCs has been reported also on random Poly-L-lactic acid (PLLA) fibers, due to cytoskeletal rearrangements and tensions, which in turn influence intracellular mechanotransductive pathways (Yin et al., 2015). In fact, when the cells were treated with Rho kinase (ROCK) inhibitor Y-27632 (inhibitor of myosin-generated cytoskeletal tension), loss of lineage commitment was detected, and cells' morphology was not affected by the fibers topography.

The works here summarized and the others conducted on the interaction of MSCs with electrospun substrates (Tables 1, 2) demonstrate that networks of polymer fibers (random, aligned and hierarchical) are effective in providing topographical and physical cues to guide differentiation of stem cells. These observations have led to the development of bioinspired scaffolds with potential future implications in diverse clinical areas, including the regeneration and repair of bone, tendon, ligament, dentin, and skin.

\section{Human Umbilical Vein Endothelial Cells}

Vascular endothelial cells are of fundamental importance for the entire circulatory system, because they are involved in fluid filtration, homeostasis and prevention of thrombosis (Rajendran et al., 2013). Endothelial cells and particularly HUVECs, which are isolated from human umbilical cord veins, are widely used to study cardiovascular diseases and develop biomedical devices for vascular tissue engineering (Lei et al., 2016). One important aspect to consider when designing scaffolds for endothelial cells is the role played by surface topography, at micro- and nanoscale, on cell adhesion, proliferation and migration, to create a physiological environment that stimulates the formation of a functional endothelium.

A recent work of Ahmed and co-workers has reported on the influence of the diameter of electrospun fibers on HUVECs migration (Ahmed et al., 2018). Aligned poly(lactic-co-glycolic acid) (PLGA) fibers with five different diameters $(0.5,1,2$, 4 , and $10 \mu \mathrm{m}$ ) were analyzed. The greater cell displacement in a scratch wound assay was measured for HUVECs seeded on fibers with intermediate diameter ( 1 and $2 \mu \mathrm{m})$ with peak migration velocity of $24 \mu \mathrm{m} / \mathrm{h}$ after $12 \mathrm{~h}$ of cell culture. HUVECs were able also to move on scaffolds with $0.5 \mu \mathrm{m}$ size fibers 
but at lower migration rates. On these scaffolds cell alignment and polarization, and higher levels of FAK expression were detected. FAK is a non-receptor tyrosine kinase that regulates cell shape, adhesion and motility. The fiber diameter influenced the focal adhesion of HUVECs but not their metabolism or the formation of cell-matrix anchorage points. At $12 \mathrm{~h}$, a significant increase in phosphorylated FAK (pFAK, associated with actin regulation and adhesion dynamics) was detected, which is linked to the peak migration velocity. On the contrary, limited cell motility was observed for scaffolds with 4 and $10 \mu \mathrm{m}$ fibers. Investigations of the spatial distribution of pFAK revealed that pFAK was localized in the HUVECs cytosol for $0.5,1.0$, and $2.0 \mu \mathrm{m}$ fibers, and at the cell periphery for 4 and $10 \mu \mathrm{m}$ fibers (non-uniform distribution). This promoted uniaxial cell morphology and stimulated the migratory process to occur preferentially along the fiber longitudinal direction for scaffolds with intermediate fiber diameter. A similar conclusion has been drawn by other researchers working on HUVECs cultured on micropatterned scaffolds with spatially heterogeneous alignment of poly(D,L-lactide) (PDLLA)/PCL electrospun fibers of 0.5$1 \mu \mathrm{m}$ size (Xu et al., 2015). Fibrous scaffolds with patterns of random and well-aligned PDLLA/PCL fibers were prepared using a wire spring as template collector. It was observed that the micropatterned scaffolds induced the proliferation of HUVECs and modifications to their cytoskeleton morphology (Figure 1). The lowest values of mean cell body shape index (a parameter indicating the degree of cell polarization) were measured for cells cultured on patterned scaffolds having the longest distance $(1,500 \mu \mathrm{m})$ between regions with random and aligned fibers, indicating the highest degree of cell polarization and alignment. Furthermore, those scaffolds stimulated the cells to express high levels of angiogenesis-related genes and therefore they have potential applications in vascular tissue engineering. The combination of electrospinning and micro-pattering techniques has proven to be effective for creating hierarchical biointerfaces that direct the arrangement of endothelial cells and their biological functions (Shin et al., 2017; Yan et al., 2017).
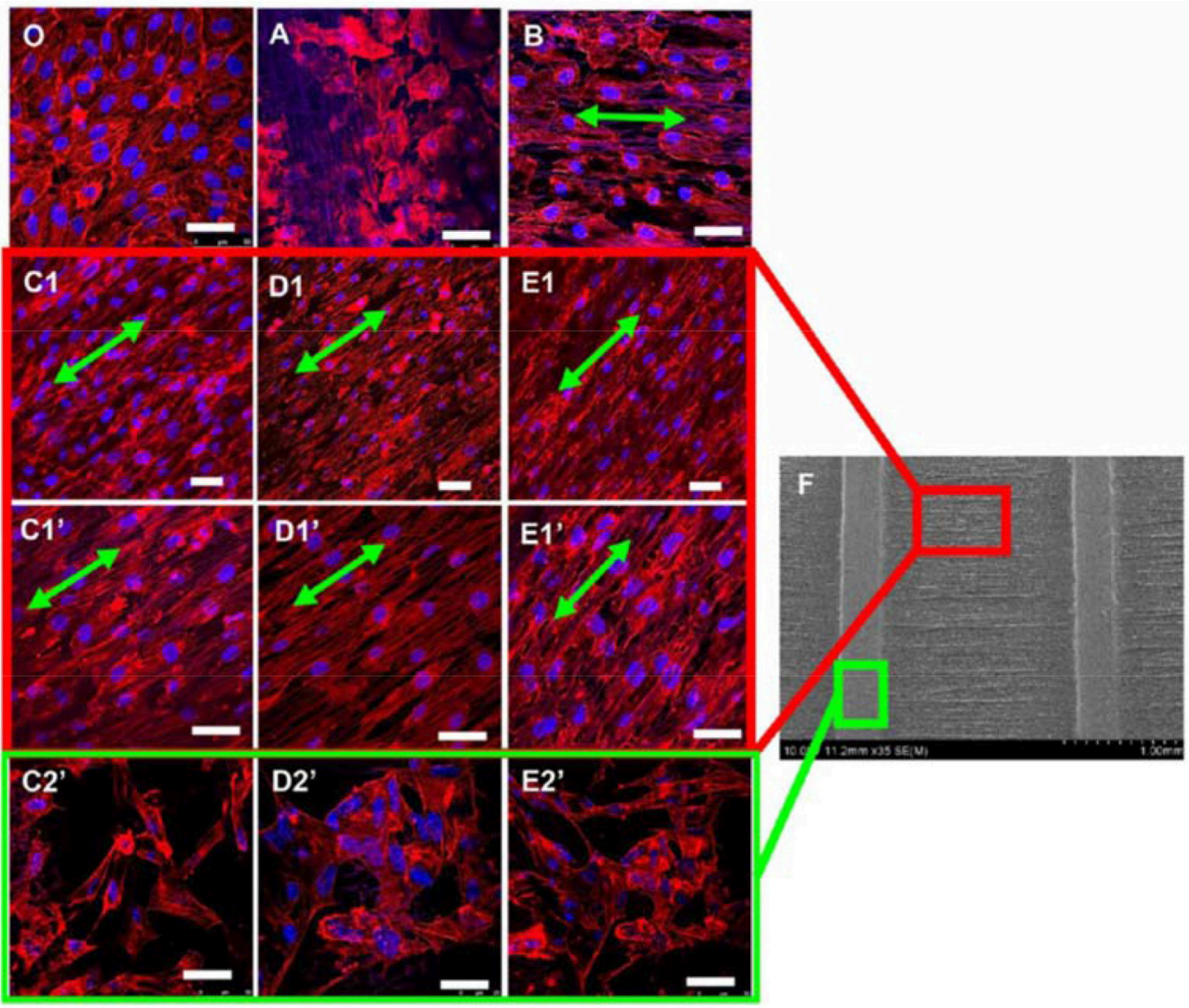

FIGURE 1 | Confocal images of HUVECs (actin filaments in red and nuclei in blue) cultured for 7 days on (O) standard petri dish (typical cobblestone-like structure) and electrospun scaffolds with different patterns: (A) nonwoven (cells with flat, round shape morphology); (B) single directionally aligned pattern (cell alignment along fibers direction, green arrows); (C1-E1) anisotropic aligned patterns with interval distances of 300, 800, and 1500 $\mu \mathrm{m}$, respectively; (C1' 'E1') anisotropic aligned patterns with interval distances of 300,800 , and $1500 \mu \mathrm{m}$ (high magnification images), respectively (spindle shape along the long fiber axes for cells between the embossments) (C2' - E2') anisotropic aligned patterns with interval distances of 300, 800, and $1500 \mu \mathrm{m}$, respectively (polygonal shape with random stretching for cells on the embossments). (F) SEM image of anisotropic aligned pattern. Scale bar $=50 \mu \mathrm{m}$. Reprinted with permission from Xu et al. (2015). Copyright 2018 of the American Chemical Society. 


\section{COMPUTATIONAL MODELS}

The literature that has been discussed so far in this review provides experimental evidences that the surface topography of biomaterials influences cellular behavior, including cells' alignment, elongation, migration, phenotype transitions and differentiation. In vitro and in vivo studies are incredibly beneficial to collect data and results on how artificially created micro- and nano-features perform in realistic applications (Tables 1, 2). The underlying mechanisms of cell-material interactions are only partially understood and further investigations are required to define the best scaffold design for promoting the regeneration of a target tissue (Kennedy et al., 2017; Paim et al., 2018). However, time and cost requirements for in vitro and in vivo tests pose limitations on the use of and reliance on experimental studies alone, together with ethical issues when animal models are concerned. Computational modeling has the significant advantage of facilitating research by conducting thousands of simulated trials with a wide range of variations and for a plethora of complex biological systems (Geris et al., 2018).

Albert and Schwarz have developed mathematical models to predict the dynamics of cell shape and forces on micropatterned substrates (Albert and Schwarz, 2014, 2016a,b). Their models are based on the cellular Potts model (CPM) that allows to simulate the behavior of single or interacting cells by describing them as internally structureless but spatially extended objects on a regular lattice (Voss-Böhme, 2012; Tartarini and Mele, 2015). The number of lattice sites belonging to a single cell defines the area occupied by the cell. By changing the lattice resolution and the indices of the lattice sites, cells with arbitrary shape and shape evolutions can be represented. Initially, the authors compared simulations with experimental data on single cell attached on crossbow, $\mathrm{Y}$ and $\mathrm{H}$ patterns (Albert and Schwarz, 2014). The model well described how the cell contour adapted to the pattern's geometry and reconstructed the traction forces in agreement with experiments. The forces were higher at the extremities of the patterns (adhesive edges of the contour) and increased with the curvature of the contour depending on the availability of receptors for focal adhesion. The CPM-based model was then used to predict the collective behavior of cells on micropatterns, including cell division, cell-cell contacts and migration (Albert and Schwarz, 2014). The model predicted, for example, that for a cell dividing on a $\mathrm{L}$ shaped pattern, the two daughter cells were most likely to be located on the two arms of the $\mathrm{L}$, as confirmed by experimental results. In order to identify the optimal adhesive patterns to control cell functions, CPM was combined with genetic algorithms (GAs) (Albert and Schwarz, 2016c) (Figure 2), which are computational techniques inspired by natural evolution for the heuristic search of problem solutions (McCall, 2005). The migration of cells on rachet micropatterns in a linear arrangement was analyzed and the algorithm predicted that a triangular shape was ideal to guide cell migration in the direction of the tip of the triangle, as also demonstrated experimentally. Differently from what expected though, the most effective pattern to achieve unidirectional migration of cells consisted of asymmetric triangles that were rotated and

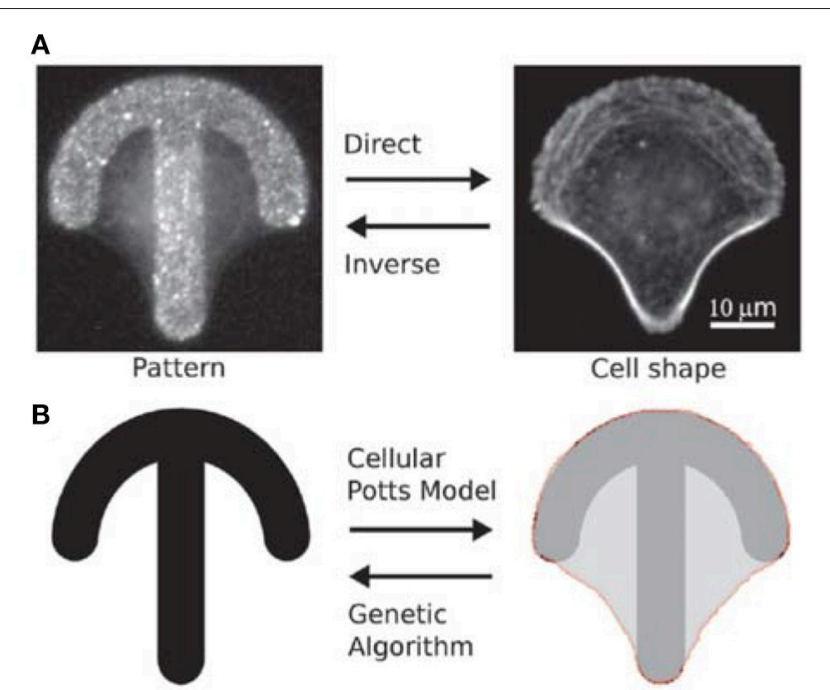

FIGURE 2 | (A) Fluorescence images of a HeLa cell stained for actin on a crossbow microstructure coated with fibronectin. Given a micro-pattern, cell shape can be observed with optical microscopy (direct problem). Give a cell shape, it is not always straightforward to experimentally identify the original pattern (inverse problem). (B) CPM can be used to predict cell shape on a microstructure, and genetic algorithms can help to define pattern geometry. Reproduced with permission from Albert and Schwarz (2016c). Copyright 2016 of the Royal Society of Chemistry.

connected to one another to form a pattern with an almost straight horizontal edge. The computational model developed is a useful tool to predict cell interactions with structured scaffolds and it can be adapted to simulate diverse cellular processes.

With a distinct lack of literature on computational/numerical modeling that predicts how cells interact with electrospun nanofibrous structures (role of roughness and topography), there is a clear gap in the field which has great potential if correctly pursued. This will open even more possibilities to design and create novel fibrous scaffolds with engineered surface structures (Ziebert and Aranson, 2016). For example, computer aided characterization of complex biointerfacial interactions of specific polymer fibers could be created. Computational algorithms and numerical solutions could be formulated to generate a method of predicting the most suitable surface topography of electrospun mats for specific cells and to prompt tissue regeneration processes. In the development of computational models that describe how cell behavior is affected by the surface properties of electrospun scaffolds, geometrical parameters to be considered include fibers diameter, fibers organization and degree of alignment, porosity of the mat, presence of nanostructures or nanopores on single fiber surface, overall roughness of the electrospun mat. All these aspects have been evaluated experimentally, as discussed in the previous section of this mini review.

\section{CONCLUSIONS}

Electrospun nanofibers have become vital structures for a plethora of different applications, with the field of biomedical 
TABLE 3 | Clinical trials of electrospun scaffolds.

\begin{tabular}{|c|c|c|c|c|c|c|}
\hline Study & Status & Condition/disease & Aim & $\begin{array}{l}\text { Number of } \\
\text { participants }\end{array}$ & Scaffold & Results \\
\hline $\begin{array}{l}\text { Experimental study of } \\
\text { the vascular prosthesis } \\
\text { manufactured by } \\
\text { electrospinning } \\
\text { (NCT02255188) }\end{array}$ & Completed & $\begin{array}{l}\text { Arterial occlusive } \\
\text { disease }\end{array}$ & $\begin{array}{l}\text { Determination of the safety } \\
\text { of electrospun vascular } \\
\text { grafts for the development } \\
\text { of thrombosis. }\end{array}$ & 120 & $\begin{array}{l}\text { PCL grafts; PCL/gelatin } \\
\text { grafts; } \\
\text { PLGA/PCL/gelatin } \\
\text { grafts; Nylon } 6 \text { grafts. }\end{array}$ & $\begin{array}{l}\text { Not currently } \\
\text { available }\end{array}$ \\
\hline $\begin{array}{l}\text { EktoTherix } \\
\text { regenerative tissue } \\
\text { scaffold for repair of } \\
\text { surgical excision } \\
\text { wounds } \\
\text { (NCT02409628) }\end{array}$ & Completed & $\begin{array}{l}\text { Non-melanoma } \\
\text { skin cancer; Basal } \\
\text { cell carcinoma; } \\
\text { Squamous cell } \\
\text { carcinoma }\end{array}$ & $\begin{array}{l}\text { Assessment of the safety } \\
\text { and performance of } \\
\text { EktoTherix }{ }^{T M} \text { Tissue Repair } \\
\text { Scaffold for the treatment of } \\
\text { full-thickness, dermatologic } \\
\text { wounds due to the surgical } \\
\text { removal of non-melanoma } \\
\text { skin cancers. }\end{array}$ & 12 & $\begin{array}{l}\text { EktoTherix }{ }^{\mathrm{TM}} \text { Tissue } \\
\text { Repair Scaffold: }\end{array}$ & $\begin{array}{l}\text { Not currently } \\
\text { available }\end{array}$ \\
\hline $\begin{array}{l}\text { Clinical trial for the } \\
\text { treatment of diabetic } \\
\text { foot ulcers using a nitric } \\
\text { oxide releasing patch: } \\
\text { PATHON }\end{array}$ & Completed & Diabetic foot & $\begin{array}{l}\text { Evaluation of the } \\
\text { effectiveness and safety of } \\
\text { nitric oxide releasing wound } \\
\text { dressings for the treatment } \\
\text { of diabetic foot ulcers. }\end{array}$ & 100 & $\begin{array}{l}\text { Multilayer polymeric } \\
\text { transdermal patch with } \\
\text { a continuous release of } \\
\text { nitric oxide } \\
\text { (polyurethane-based } \\
\text { fibers). }\end{array}$ & $\begin{array}{l}\text { Not currently } \\
\text { available }\end{array}$ \\
\hline $\begin{array}{l}\text { Controlled nitric oxide } \\
\text { releasing patch vs. } \\
\text { meglumine antimoniate } \\
\text { in the treatment of } \\
\text { cutaneous } \\
\text { Leishmaniasis }\end{array}$ & Terminated & $\begin{array}{l}\text { Cutaneous } \\
\text { Leishmaniasis }\end{array}$ & $\begin{array}{l}\text { Evaluation of the } \\
\text { effectiveness of a nitric } \\
\text { oxide topical donor for the } \\
\text { treatment of cutaneous } \\
\text { leishmaniasis. }\end{array}$ & 178 & $\begin{array}{l}\text { Multilayer polymeric } \\
\text { transdermal patch with } \\
\text { a continuous release of } \\
\text { nitric oxide } \\
\text { (polyurethane-based } \\
\text { fibers). }\end{array}$ & $\begin{array}{l}\text { Not currently } \\
\text { available }\end{array}$ \\
\hline
\end{tabular}

The data are obtained from ClinicalTrials.gov, a resource provided by the U.S. National Library of Medicine (Accessed on September 2018).

engineering being, arguably, one of the most important. Thanks to the versatility of electrospinning, nanofibrous scaffolds can be tailored and modified to improve their biocompatibility for applications such as tissue engineering, drug delivery and wound dressings. For example, electrospun mats have been used in clinical studies for the treatment of arterial occlusive disease, skin cancer and diabetic foot (Table 3). As discussed in this review, fiber alignment, micropatterning, and controlled porosity of nanofibrous mats have all been found to have significant effect on cellular behavior, inducing cell attachment, migration and differentiation. Extensive research has been conducted on exploring morphological cues provided by $2 \mathrm{D}$ electrospun mats, and only recently fibrous $3 \mathrm{D}$ scaffolds have been proposed to closely mimic the ECM structure (Cai et al., 2013; Lee et al., 2014; Cho et al., 2016; Hwang et al., 2018; Unnithan et al., 2018). The studies conducted so far have demonstrated that a fine tuning of the $3 \mathrm{D}$ porosity of the electrospun scaffolds is crucial to promote cell infiltration. Future research in the field should combine experimental studies with numerical and

\section{REFERENCES}

Abarzúa-Illanes, P. N., Padilla, C., Ramos, A., Isaacs, M., Ramos-Grez, J., Olguín, H. C., et al. (2017). Improving myoblast differentiation on electrospun poly(E-caprolactone) scaffolds. J. Biomed. Mater. Res. A. 105, 2241-2251. doi: 10.1002/jbm.a.36091 computational modeling for the design and fabrication of novel micro- and nanostructured 3D scaffolds. Computer aided simulations could not only be used to predict cell interaction with specific topography but be formulated in a manner which then advises on the most suitable functional group (or biological molecule) that ought to be immobilized on the surface or embedded within the scaffold. This would require taking in consideration a complex combination of parameters that include the chemical composition of the scaffold (exposed chemical groups, wetting properties, and biodegradation), micro- and nano-porosity, organization of the fibrous network (random or aligned fibers) and mechanical properties of the scaffold.

\section{AUTHOR CONTRIBUTIONS}

$\mathrm{AD}$ and EM contributed to the conception and design of the study. AD and EM wrote the first draft of the manuscript. DT wrote sections of the manuscript. All authors contributed to manuscript revision, read and approved the submitted version. 
Albert, P. J., and Schwarz, U. S. (2014). Dynamics of cell shape and forces on micropatterned substrates predicted by a cellular Potts model. Biophys. J. 106, 2340-2352. doi: 10.1016/j.bpj.2014.04.036

Albert, P. J., and Schwarz, U. S. (2016a) Modeling cell shape and dynamics on micropatterns. Cell Adh. Migrat. 10, 516-528. doi: 10.1080/19336918.2016.1148864

Albert, P. J., and Schwarz, U. S. (2016b) Dynamics of cell ensembles on adhesive micropatterns: bridging the gap between single cell spreading and collective cell migration. PLoS Comput. Biol. 12:e1004863. doi: 10.1371/journal.pcbi.1004863

Albert, P. J., and Schwarz, U. S. (2016c) Optimizing micropattern geometries for cell shape and migration with genetic algorithms. Integr. Biol. 11, 741-750. doi: 10.1039/c6ib00061d

Anderson, H. J., Sahoo, J. K., Ulijn, R. V., and Dalby, M. J. (2016). Mesenchymal stem cell fate: applying biomaterials for control of stem cell behaviour. Front. Bioeng. Biotechnol. 4:38. doi: 10.3389/fbioe.2016.00038

Baudequin, T., Gaut, L., Mueller, M., Huepkes, A., Glasmacher, B., Duprez, D., et al. (2017). The osteogenic and tenogenic differentiation potential of C3H10T1/2 (mesenchymal stem cell model) cultured on PCL/PLA electrospun scaffolds in the absence of specific differentiation medium. Materials 10:E1387. doi: 10.3390/ma10121387

Bergmeister, H., Schreiber, C., Grasl, C., Walter, I., Plasenzotti, R., Stoiber, M., et al. (2013). Healing characteristics of electrospun polyurethane grafts with various porosities. Acta Biomater. 9, 6032-6040. doi: 10.1016/j.actbio.2012.12.009

Bhardwaj, N., and Kundu, S. C. (2010). Electrospinning: a fascinating fiber fabrication technique. Biotechnol. Adv. 28, 325-347. doi: 10.1016/j.biotechadv.2010.01.004

Binan, L., Tendey, C., De Crescenzo, G., El Ayoubi, R., Ajji, A., and Jolicoeur, M. (2014). Differentiation of neuronal stem cells into motor neurons using electrospun poly-L-lactic acid/gelatin scaffold. Biomater 35, 664-674. doi: 10.1016/j.biomaterials.2013.09.097

Cai, S., Xu, H., Jiang, Q., and Yang, Y. (2013). Novel 3D electrospun scaffolds with fibers oriented randomly and evenly in three dimensions to closely mimic the unique architectures of extracellular matrices in soft tissues: fabrication and mechanism study. Langmuir 29, 2311-2318. doi: 10.1021/la304414j

Cho, M., Kim, S. H., Jin, G., Park, K. I., and Jang, J. H. (2016). Salt-induced electrospun patterned bundled fibers for spatially regulating cellular responses. ACS Appl. Mater. Interfaces 8, 13320-13331. doi: 10.1021/acsami.6b03848

Cirillo, V., Clements, B. A., Guarino, V., Bushman, J., Kohn, J., and Ambrosio, L. (2014). A comparison of the performance of mono- and bi-component electrospun conduits in a rat sciatic model. Biomaterials 35, 8970-8982. doi: 10.1016/j.biomaterials.2014.07.010

Dalby, M. J., Gadegaard, N., and Oreffo, R. O. C. (2014). Harnessing nanotopography and integrin-matrix interactions to influence stem cell fate. Nat. Mater. 13, 558-569. doi: 10.1038/nmat3980

Dalby, M. J., García, A. J., and Salmeron-Sanchez, M. (2018). Receptor control in mesenchymal stem cell engineering. Nat. Rev. Mater. 3:17091. doi: $10.1038 /$ natrevmats.2017.91

Fioretta, E. S., Simonet, M., Smits, A. I., Baaijens, F. P., and Bouten, C. V. (2014). Differential response of endothelial and endothelial colony forming cells on electrospun scaffolds with distinct microfiber diameters. Biomacromolecules 15, 821-829. doi: 10.1021/bm4016418

Geiger, B., Bershadsky, A., Pankov, R., and Yamada, K. M. (2001). Transmembrane extracellular matrix-cytoskeleton crosstalk. Nat. Rev. Molec. Cell Biol. 2, 793-805. doi: 10.1038/35099066

Geris, L., Lambrechts, T., Carlier, A., and Papantoniou, I. (2018). The future is digital: in silico tissue engineering. Curr. Opinion Biomed. Eng. 6, 92-98. doi: 10.1016/j.cobme.2018.04.001

Ghosh, L. D., Jain, A., Sundaresan, N. R., and Chatterjee, K. (2018). Elucidating molecular events underlying topography mediated cardiomyogenesis of stem cells on 3D nanofibrous scaffolds. Mater. Sci. Eng. C 88, 104-114. doi: $10.1016 /$ j.msec.2018.03.012

Hajiali, H., Contestabile, A., Mele, E., and Athanassiou, A. (2018). Influence of topography of nanofibrous scaffolds on functionality of engineered neural tissue. J. Mater. Chem. B 6, 930-939. doi: 10.1039/C7TB02969A

Hwang, T. I., Maharjan, B., Tiwari, A. P., Lee, S., Joshi, M. K., Park, C. H., et al. (2018). Facile fabrication of spongy nanofibrous scaffold for tissue engineering applications. Mater. Lett. 219, 119-122. doi: 10.1016/j.matlet.2018.02.040
Jiang, T., Kai, D., Liu, S., Huang, X., Heng, S., Zhao, J., et al. (2018). Mechanically cartilage-mimicking poly(PCL-PTHF urethane)/collagen nanofibers induce chondrogenesis by blocking NF-kappa B signalling pathway. Biomaterials 178, 281-292. doi: 10.1016/j.biomaterials.2018.06.023

Jiang, W., Li, L., Zhang, D., Huang, S., Jing, Z., Wu, Y., et al. (2015). Incorporation of aligned PCL-PEG nanofibers into porous chitosan scaffolds improved the orientation of collagen fibers in regenerated periodontium. Acta Biomater. 25, 240-252. doi: 10.1016/j.actbio.2015.07.023

Jin, L., Hu, B., Li, Z., Li, J., Gao, Y., Wang, Z., et al. (2018). Synergistic effects of electrical stimulation and aligned nanofibrous microenvironment on growth behavior of mesenchymal stem cells. ACS Appl. Mater. Interfaces 10, 18543-18550. doi: 10.1021/acsami.8b04136

Jun, I., Chung, Y. W., Heo, Y. H., Han, H. S., Park, J., Jeong, H., et al. (2016). Creating hierarchical topographies on fibrous platforms using femtosecond laser ablation for directing myoblasts behaviour. ACS Appl. Mater. Interfaces 8, 3407-3417. doi: 10.1021/acsami.5b11418

Kanchanawong, P., Shtengel, G., Pasapera, A. M., Ramko, E. B., Davidson, M. W., Hess, H. F., et al. (2010). Nanoscale architecture of integrin-based cell adhesions. Nature 468, 580-584. doi: 10.1038/nature09621

Kennedy, K. M., Bhaw-Luximon, A., and Jhurry, D. (2017). Cell-matrix mechanical interaction in electrospun polymeric scaffolds for tissue engineering: implications for scaffold design and performance. Acta Biomater. 50, 41-55. doi: 10.1016/j.actbio.2016.12.034

Khorshidi, S., Solouk, A., Mirzadeh, H., Mazinani, S., Lagaron, J. M., Sharifi, S., et al. (2016). A review of key challenges of electrospun scaffolds for tissue engineering applications. J. Tissue Eng. Regen. Med. 10, 715-738. doi: $10.1002 /$ term. 1978

Lee, S., Cho, S., Kim, M., Jin, G., Jeong, U., and Jang, J. H. (2014). Highly moldable electrospun clay-like fluffy nanofibers for three-dimensional scaffolds. ACS Appl. Mater. Interfaces 6, 1082-1091. doi: 10.1021/am404627r

Lei, J., Peng, S., Samuel, S. B., Zhang, S., Wu, Y., Wang, P., et al. (2016). A simple and biosafe method for isolation of human umbilical vein endothelial cells Anal. Biochem. 508, 15-18. doi: 10.1016/j.ab.2016.06.018

Li, Y., Xiao, Y., and Liu, C. (2017). The horizon of materiobiology: a perspective on material-guided cell behaviours and tissue engineering. Chem. Rev. 117, 4376-4421. doi: 10.1021/acs.chemrev.6b00654

Lin, J., Zhou, W., Han, S., Bunpetch, V., Zhao, K., Liu, C., et al. (2018). Cellmaterial interactions in tendon tissue engineering. Acta Biomater. 70, 1-11. doi: 10.1016/j.actbio.2018.01.012

Lin, Z., Zhao, X., Chen, S., and Du, C. (2017). Osteogenic and tenogenic induction of hBMSCs by an integrated nanofibrous scaffold with chemical and structural mimicry of the bone-ligament connection. J. Mater. Chem. B 5, 1015-1027. doi: 10.1039/C6TB02156E

Liu, X., and Wang, S. (2014). Three-dimensional nano-biointerface as a new platform for guiding cell fate. Chem. Soc. Rev. 43, 2385-2401. doi: $10.1039 / \mathrm{C} 3 \mathrm{CS} 60419 \mathrm{E}$

Liu, Y., Yang, G., Ji, H., Xiang, T., Luo, E., and Zhou, S. (2017). Synergetic effect of topological cue and periodic mechanical tension-stress on osteogenic differentiation of rat bone mesenchymal stem cells. Colloids Surf. B Biointerfaces 154, 1-9. doi: 10.1016/j.colsurfb.2017.02.035

Lutolf, M. P., and Hubbell, J. A. (2005). Synthetic biomaterials as instructive extracellular microenvironments for morphogenesis in tissue engineering. Nat. Biotech. 23, 47-55. doi: 10.1038/nbt1055

Lv, F. J., Tuan, R. S., Cheung, K. M., and Leung, V. Y. (2014). Concise review: the surface markers and identity of human mesenchymal stem cells. Stem Cells 32, 1408-1419. doi: 10.1002/stem.1681

Malkoc, V., Gallego-Perez, D., Nelson, T., Lannutti, J. J., and Hansford, D. J. (2015). Controlled neuronal cell patterning and guided neurite growth on micropatterned nanofiber platforms. J. Micromech. Microeng. 25:125001. doi: 10.1088/0960-1317/25/12/125001

Marino, A., Genchi, G. G., Sinibaldi, E., and Ciofani, G. (2017). Piezoelectric effects of materials on bio-interfaces. ACS Appl. Mater. Interfaces 9, 17663-17680. doi: 10.1021 /acsami.7b04323

Mattila, P. K., and Lappalainen, P. (2008). Filopodia: molecular architecture and cellular functions. Nat. Rev. Mol. Cell Biol. 9, 446-454. doi: 10.1038/nrm2406

McCall, J. (2005). Genetic algorithms for modelling and optimisation. J. Computat. Appl. Mathemat. 184, 205-222. doi: 10.1016/j.cam.2004.07.034 
Mele, E. (2016). Electrospinning of natural polymers for advanced wound care: towards responsive and adaptive dressings. J. Mater. Chem. B 4, 4801-4812. doi: 10.1039/C6TB00804F

Mele, E., Heredia-Guerrero, J. A., Bayer, I. S., Ciofani, G., Genchi, G. G., Ceseracciu, L., et al. (2015). Zwitterionic nanofibers of super-glue for transparent and biocompatible multi-purpose coatings. Sci. Rep. 5:14019. doi: $10.1038 /$ srep 14019

Nedjari, S., Awaja, F., and Altankov, G. (2017). Three dimensional honeycomb patterned fibrinogen based nanofibers induce substantial osteogenic response of mesenchymal stem cells. Sci Rep. 7:15947. doi: 10.1038/s41598-01715956-8

Paim, Á., Tessaro, I. C., Cardozo, N. S. M., and Pranke, P. (2018). Mesenchymal stem cell cultivation in electrospun scaffolds: mechanistic modeling for tissue engineering. J. Biol. Phys. 44, 245-271. doi: 10.1007/s10867-0189482-y

Park, S. H., Kim, M. S., Lee, B., Park, J. H., Lee, H. J., Lee, N. K., et al. (2016). Creation of a hybrid scaffold with dual configuration of aligned and random electrospun fibers. ACS Appl. Mater. Interfaces 8, 2826-2832. doi: 10.1021/acsami.5b11529

Rahman, S. U., Oh, J. H., Cho, Y. D., Chung, S. H., Lee, G., Baek, J. H., et al. (2018). Fibrous topography-potentiated canonical Wnt signaling directs the odontoblastic differentiation of dental pulp-derived stem cells. ACS Appl. Mater. Interfaces 10, 17526-17541. doi: 10.1021/acsami.7b19782

Rajendran, P., Rengarajan, T., Thangavel, J., Nishigaki, Y., Sakthisekaran, D., Sethi, G., et al. (2013). The vascular endothelium and human diseases. Int. J. Biol. Sci. 9, 1057-1069. doi: 10.7150/ijbs.7502

Sankar, S., Kakunuri, M., D., Eswaramoorthy, S., Sharma, C. S., and Rath, S. N. (2018). Effect of patterned electrospun hierarchical structures on alignment and differentiation of mesenchymal stem cells: biomimicking bone. J. Tissue Eng. Regen. Med. 12, e2073-e2084. doi: 10.1002/term.2640

Sharma, R. R., Pollock, K., Hubel, A., and McKenna, D. (2014). Mesenchymal stem or stromal cells: a review of clinical applications and manufacturing practices. Transfusion 54, 1418-1437. doi: 10.1111/trf.12421

Shin, Y. M., Shin, H. J., Heo, Y., Jun, I., Chung, Y. W., Kim, K., et al. (2017). Engineering an aligned endothelial monolayer on a topologically modified nanofibrous platform with a micropatterned structure produced by femtosecond laser ablation. J. Mater. Chem. B 5, 318-328. doi: $10.1039 / \mathrm{C} 6 \mathrm{~TB} 02258 \mathrm{H}$

Sill, T., and von Recum, H. A. (2008). Electrospinning: applications in drug delivery and tissue engineering. Biomater 29, 1989-2006. doi: 10.1016/j.biomaterials.2008.01.011

Su, N., Gao, P. L., Wang, K., Wang, J. Y., Zhong, Y., and Luo, Y. (2017). Fibrous scaffolds potentiate the paracrine function of mesenchymal stem cells: a new dimension in cell-material interaction. Biomater 141, 74-85. doi: 10.1016/j.biomaterials.2017.06.028

Sun, L., Gao, W., Fu, X., Shi, M., Xie, W., Zhang, W., et al. (2018). Enhanced wound healing in diabetic rats by nanofibrous scaffolds mimicking the basket weave pattern of collagen fibrils in native skin. Biomater. Sci. 6, 340-349. doi: 10.1039/C7BM00545H

Tallawi, M., Dippold, D., Rai, R., D’Atri, D., Roether, J. A., Schubert, D. W., et al. (2016). Novel PGS/PCL electrospun fiber mats with patterned topographical features for cardiac patch applications. Mater. Sci. Eng. C Mater. Biol. Appl. 69, 569-576. doi: 10.1016/j.msec.2016.06.083

Tartarini, D., and Mele, E. (2015). Adult stem cell therapies for wound healing: biomaterials and computational models. Front. Bioeng. Biotechnol. 3:206. doi: $10.3389 /$ fbioe. 2015.00206

Taskin, M. B., Xia, D., Besenbacher, F., Dong, M., and Chen, M. (2017). Nanotopography featured polycaprolactone/polyethyleneoxide microfibers modulate endothelial cell response. Nanoscale 9, 9218-9229. doi: $10.1039 / \mathrm{C} 7 \mathrm{NR} 03326 \mathrm{E}$
Unnithan, A. R., Sasikala, A. R. K., Thomas, S. S., Nejad, A. G., Cha, Y. S., Park, C. H., et al. (2018). Strategic design and fabrication of biomimetic 3d scaffolds: unique architectures of extracellular matrices for enhanced adipogenesis and soft tissue reconstruction. Sci Rep. 8:5696. doi: 10.1038/s41598-018-23966-3

Voss-Böhme, A. (2012). Multi-scale modeling in morphogenesis: a critical analysis of the cellular Potts model. PLoS ONE 7:e42852. doi: 10.1371/journal.pone.0042852

Xia, H., and Xia, Y. (2018). An in vitro study of non-aligned or aligned electrospun poly(methyl methacrylate) nanofibers as primary rat astrocytesloading scaffold. Mater. Sci. Eng. 91, 228-235. doi: 10.1016/j.msec.2018.05.050

Xie, J., Li, X., and Xia, Y. (2008). Putting electrospun nanofibers to work for biomedical research. Macromol. Rapid Comm. 29, 1775-1792. doi: 10.1002/marc.200800381

Xie, J., Liu, W., MacEwan, M. R., Bridgman, P. C., and Xia, Y. (2014). Neurite outgrowth on electrospun nanofibers with uniaxial alignment: the effects of fiber density, surface coating, and supporting substrate. ACS Nano. 8, 1878-1885. doi: $10.1021 / \mathrm{nn} 406363 \mathrm{j}$

Xu, H., Li, H., Ke, Q., and Chang, J. (2015). An anisotropically and heterogeneously aligned patterned electrospun scaffold with tailored mechanical property and improved bioactivity for vascular tissue engineering. ACS Appl. Mater. Interfaces 7, 8706-8718. doi: 10.1021/acsami.5b00996

Xue, J., Yang, J., O’Connor, D. M., Zhu, C., Huo, D., Boulis, N. M., et al. (2017). Differentiation of bone marrow stem cells into schwann cells for the promotion of neurite outgrowth on electrospun fibers. ACS Appl. Mater. Interfaces 9, 12299-12310. doi: 10.1021/acsami.7b00882

Yan, S., Zhang, X., Zhang, L., Liu, H., Wang, X., and Li, Q. (2017). Polymer scaffolds for vascular tissue engineering fabricated by combined electrospinning and hot embossing. Biomed. Mater. 13:015003. doi: 10.1088/1748-605X/aa8a81

Yang, G. H., Jeon, H., and Kim, G. (2017). Alternately plasma-roughened nanosurface of a hybrid scaffold for aligning myoblasts. Biofabrication 9:025035. doi: 10.1088/1758-5090/aa77ba

Yin, Z., Chen, X., Song, H. X., Hu, J. J., Tang, Q. M., Zhu, T., et al. (2015). Electrospun scaffolds for multiple tissues regeneration in vivo through topography dependent induction of lineage specific differentiation. Biomaterials 44, 173-185. doi: 10.1016/j.biomaterials.2014.12.027

Zhang, L.-H., Duan, X.-P., Yan, X., Yu, M., Ning, X., Zhao, Y., et al. (2016). Recent advances in melt electrospinning. RSC Adv. 6, 53400-53414. doi: 10.1039/C6RA09558E

Zhang, Q., Hwang, J. W., Oh, J. H., Park, C. H., Chung, S. H., Lee, Y. S., et al. (2017). Effects of the fibrous topography-mediated macrophage phenotype transition on the recruitment of mesenchymal stem cells: an in vivo study. Biomater 149, 77-87. doi: 10.1016/j.biomaterials.2017.10.007

Zhu, M., Wang, Z., Zhang, J., Wang, L., Yang, X., Chen, J., et al. (2015). Circumferentially aligned fibers guided functional neoartery regeneration in vivo. Biomater 61, 85-94. doi: 10.1016/j.biomaterials.2015.05.024

Ziebert, F., and Aranson, I. S. (2016). Computational approaches to substrate-based cell motility. Comput. Mater. 2:16019. doi: 10.1038/npjcompumats.2016.19

Conflict of Interest Statement: The authors declare that the research was conducted in the absence of any commercial or financial relationships that could be construed as a potential conflict of interest.

Copyright (c) 2018 Denchai, Tartarini and Mele. This is an open-access article distributed under the terms of the Creative Commons Attribution License (CC BY). The use, distribution or reproduction in other forums is permitted, provided the original author(s) and the copyright owner(s) are credited and that the original publication in this journal is cited, in accordance with accepted academic practice. No use, distribution or reproduction is permitted which does not comply with these terms. 